\title{
Association of Health Literacy and Nutritional Status Assessment with Glycemic Control in Adults with Type 2 Diabetes Mellitus
}

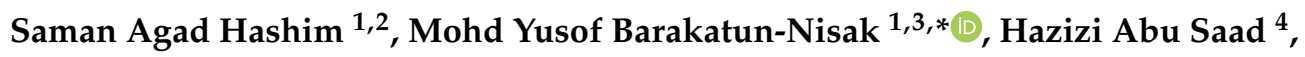 \\ Suriani Ismail ${ }^{5}$, Osama Hamdy ${ }^{6}$ and Abbas Ali Mansour ${ }^{7}$ (D) \\ 1 Department of Dietetics, Faculty of Medicine and Health Sciences, Universiti Putra Malaysia, \\ Serdang 43400, Malaysia; samman_79@yahoo.com \\ 2 Sader Teaching Hospital, Basrah Health Directorate, Ministry of Health, Basrah 61001, Iraq \\ 3 Institute for Social Sciences Studies, Universiti Putra Malaysia, Serdang 43400, Malaysia \\ 4 Department of Nutrition, Faculty of Medicine and Health Sciences, Universiti Putra Malaysia, \\ Serdang 43400, Malaysia; hazizi@upm.edu.my \\ 5 Department of Community Health, Faculty of Medicine and Health Sciences, Universiti Putra Malaysia, \\ Serdang 43400, Malaysia; si_suriani@upm.edu.my \\ 6 Joslin Diabetes Centre, Harvard Medical School, Boston, MA 02215, USA; osama.hamdy@joslin.harvard.edu \\ 7 Faiha Specialized Diabetes, Endocrine, and Metabolism Center (FDEMC), University of Basrah, \\ Basrah 61001, Iraq; abbas.mansour@fdemc.iq \\ * Correspondence: bnisak@upm.edu.my
}

Received: 9 September 2020; Accepted: 9 October 2020; Published: 15 October 2020

\begin{abstract}
While the role of medical and nutrition factors on glycemic control among adults with type 2 diabetes mellitus (T2DM) has been well-established, the association between health literacy (H.L.) and glycemic control is inconsistent. This study aims to determine the association of H.L. and nutritional status assessments with glycemic control in adults with type 2 diabetes mellitus. A total of 280 T2DM respondents (mean $(\mathrm{SD})$ age $=49.7(10.3)$ years, Glycated hemoglobin $(\mathrm{HbA1c})=9.9(2.6) \%$, and Body Mass Index $=32.7(15.1) \mathrm{kg} / \mathrm{m}^{2}$ ) were included in this study. A short-form Test of Functional Health Literacy in Adults (S-TOFHLA) assessed the H.L. levels. Nutritional status assessments included client history, glycemic control, anthropometric, and biochemical data. The mean (S.D.) H.L. score was 45.7 (24.6), with $56 \%$ of the respondents had inadequate H.L. Inadequate H.L. was more common among those females; housewives, low education, received oral antidiabetic therapy, and shorter diabetes duration. Respondents with inadequate H.L. were significantly older and had higher $\mathrm{HbA} 1 \mathrm{c}$ than those with marginal and adequate H.L. Meanwhile, respondents with inadequate and marginal H.L. levels had significantly higher total cholesterol, LDL-cholesterol, and systolic blood pressure than the respondents with adequate H.L. Low H.L. scores, self-employment status, received dual antidiabetic therapy (insulin with oral agents), received insulin alone, and had higher fasting blood glucose explained about $21 \%$ of the total variation in HbA1c (adjusted $\mathrm{R}^{2}=0.21$; $p<0.001)$. Respondents with inadequate H.L. had poor glycemic control. The H.L. scores, together with nutritional status assessments, were the factors that predicted poor glycemic control among adults with T2DM.
\end{abstract}

Keywords: health literacy; S-TOFHLA; Type 2 Diabetes Mellitus; glycemic control; Iraq

\section{Introduction}

Type 2 diabetes mellitus (T2DM) is a global public health concern, and the Middle East region is not spared with the second top diabetes rate in the world. About $10 \%$ of the patients with T2DM were 
in the Middle East region, with almost 50\% of them were undiagnosed [1]. In Iraq, the prevalence of T2DM was about 15\%, and the highest was recorded in Basrah City (19.7\%) [2]. Among those with T2DM, poor glycemic control was highly prevalent, with about $86.2 \%$ of T2DM had an HbA1c of more than $7 \%$ [3], which is consistent with the other studies worldwide [4,5]. About $40-60 \%$ of patients worldwide still have poorly controlled diabetes $[6,7]$, suggesting the critical needs to understand the factors influencing glycemic control.

In the literature, studies reported various factors contributing to poor glycemic control among T2DM patients, including diabetes duration, diabetes treatment, medical background, and nutritional status $[2,8,9]$. Although different studies have been conducted in this area, the results are inconsistent and vary across countries as well as between other ethnic groups [6,10]. Furthermore, the non-clinical factors, in particular, the concept of health literacy (H.L.), has emerged as an influential factor in the health outcomes for patients with complex chronic diseases, including T2DM [11].

H.L. is principally defined as 'the degree to which individuals can obtain, process, understand and communicate about health-related information needed to make informed health decisions' [12]. There are various instruments used to assess H.L. in the diabetes population, such as the Rapid Estimate of Adult Literacy (REALM) [13], Diabetes Numeracy Test (D.N.T.) [14], and Test of Functional Health Literacy in Adults (S-TOFHLA) [15], of which S-TOFHLA was the most commonly used and considered a suitable tool to evaluate H.L. among adults with T2DM [16]. S-TOFHLA is self-administered to assess reading comprehension by determining a patient's ability to read phrases and passages containing numbers using real objects in health care settings [17]. On the other hand, the REALM recognizes patients with low reading levels without assessing the words' understanding [13], and D.N.T. focusing only on the aspects of numeracy skills [14]. A low H.L. level is typically reported worldwide, ranging from 7.3 to $82 \%$, lowest in Switzerland, and the highest in Taiwan [18]. Nonetheless, little research exists to understand the H.L. levels in patients with T2DM in Iraq.

A study by Abdul-Hasan \& Yassin 2018 identified that Iraqi T2DM patients had inadequate H.L. levels with the mean scores of 43.3. In this study, H.L. scores were significantly associated with poor glycemic control and diabetes complications [19]. However, the mentioned study used different instruments that the author self-developed, which was not adequately validated. Also, the tool has not covered the whole spectrum of H.L. measures. S-TOFHLA is considered the best at present as it was validated in the Arabic language and measured numeracy and reading comprehension simultaneously $[15,20]$. A study conducted in Iraq used the S-TOFHLA to assess H.L. among customers who attended the pharmacies in two different cities. The study identified about $17 \%$ had low levels of H.L., which was lower as compared to the studies in Western countries [21]. The data indicate the critical needs of assessing H.L. among patients with T2DM and its association with glycemic control. Data on H.L. among T2DM is vital in designing the appropriate intervention tailored to Iraqi due to the rising number of diabetes in Iraq. Adequate H.L. promotes active participation in self-care activities leading to better glycemic control than those without adequate H.L. levels [22]. The role of medical and nutrition factors on glycemic control among adults with type 2 diabetes mellitus (T2DM) has been well-established. Nonetheless, the association between H.L. and glycemic control is still inconsistent. Therefore, this study aims to determine the association of H.L. and nutritional status assessments with glycemic control in adults with T2DM.

\section{Methods}

\subsection{Study Design and Respondents}

This cross-sectional study was conducted between January and April 2019 among respondents with T2DM at Faiha Specialized Diabetes, Endocrine, and Metabolism Centre (FDEMC), Basrah, Iraq. Respondents aged 20-64 years with a confirmed diagnosis of T2DM and had no hearing or vision impairment were included in the study. This study excluded those patients with type 1 diabetes, gestational diabetes or those with severe illness such as cancer and kidney failure. The institutional 
ethics committee approved the study (UPM/TNCPI/RMC/1.4.18.2 (JKEUPM)), and (FDEMC/ 56/35/22)), and all respondents provided their written consent before study enrolment.

\subsection{Sampling and Sample Size}

The respondents were sampled using a random sampling technique from the hospital list. Daily, about 100 patients would be attending Faiha Specialized Diabetes, Endocrine, and Metabolism Centre. According to the sample size, eight respondents were needed to be recruited daily during routine visits. Hence, we included every 12 th patient from the list as a starting point generated by SPSS. The sample size was determined using a specific formula used in a cross-sectional study conducted by Daniel [23], based on the prevalence of T2DM (19.7\%) reported among respondents with T2DM in Basrah City [2] as the following:

$$
n=(\mathrm{Z} 1-\mathrm{a} / 2) 2 p(1-p) / \mathrm{d}^{2}
$$

With a $95 \%$ confidence level and the adjustment of the $20 \%$ drop-out [23], a minimum of 280 respondents would be recruited in the study.

\subsection{Data Collection and Measurements}

Data were collected using a standardized questionnaire for nutritional status assessments that included client history, glycemic control, anthropometry, and biochemical data, as well as H.L. measurements. The client history and H.L. were collected from all the respondents when they attended Faiha Specialized Diabetes, Endocrine, and Metabolism Centre for their routine visits. The data were collected using a one-to-one interview in a particular room for about 10-15 min. The latest anthropometry and biochemical data were obtained from the medical records.

\subsubsection{Client History}

The client's history included age, sex, marital status, educational level, employment status, and monthly household income were obtained using a standardized questionnaire. Data about the duration of T2DM, treatment modalities, family history, and the presence of comorbid conditions were obtained from medical records.

\subsubsection{Health Literacy Scale}

H.L. was assessed using the Iraqi (Arabic) version of the S-TOFHLA with reported reliability of 0.65 for numeracy and 0.89 for reading scores. The questionnaire was validated in Iraqi populations [21]. S-TOFHLA consisted of both reading comprehension and numeracy competency sections with a total score of 100 points. The reading comprehension test consisted of two passages, with a total of 35 items. Each passage has few words deleted. Respondents must choose the best words to complete the sentences for each blank space using four given options. The total score for reading comprehension was 70 points. The numeracy tests included four questions that assessed the literacy-related to medications, levels of blood glucose, and appointment dates [24]. The total score for numeracy was 30 points. The score between 0 and 53 indicated as inadequate H.L.; between 54 and 66 as a marginal H.L., and those scored between 67 and 100 are recognized as having adequate H.L. [24].

\subsubsection{Anthropometry and Biochemical Data}

The body weight and height of the respondents were assessed using a standardized methodology. The weight was measured in a standing position using a digital calibrated weighing scale (SECA; British Indicators, London U.K.) to the nearest $0.1 \mathrm{~kg}$ in light clothing without shoes, watches, wallets, jewels, and other accessories that would affect the accuracy of the measurement. The height was measured without shoes or slippers using a height scale (SECA; British Indicators Ltd., London, UK) to the nearest $0.1 \mathrm{~cm}$. The respondents asked to stand straight on the stadiometer's floorboard while their backs were placed against the stadiometer's vertical backboard. Body weight and height were used 
to calculate the body mass index (B.M.I.), and the bodyweight status was classified using the World Health Organization standard. [25]. B.M.I. was classified as normal if B.M.I. was $18.5-24.9 \mathrm{~kg} / \mathrm{m}^{2}$, while overweight and obesity if B.M.I.s were $25-29.9 \mathrm{~kg} / \mathrm{m}^{2}$, and $\geq 30 \mathrm{~kg} / \mathrm{m}^{2}$, respectively [25].

Blood pressure and recent blood results for hemoglobin $\mathrm{A} 1 \mathrm{C}(\mathrm{HbA1c})$, fasting blood glucose (F.B.G.), total cholesterol (T.C.), low-density lipoprotein cholesterol (LDL-C), high-density lipoprotein cholesterol (HDL-C), and triglycerides (T.G.) were also obtained from medical records with the optimal ranges were based on the American Diabetes Associations [26].

\subsection{Statistical Analyses}

The SPSS software (I.B.M. Corp., Armonk, NY, USA, 2019) was used for data analyses, and the level of significance was set at $p<0.05$. Descriptive data were presented using means (S.D.) for continuous variables while categorical data shown using percentages and frequencies. Data were checked for normality using the Kolmogorov Smirnov statistics. HbA1c scores transformed to be normally distributed using a two-step approach [27]. Respondents were grouped according to their H.L. levels, and the mean differences were compared using one-way analyses of variance (ANOVA) for continuous data Chi-square or Fisher's exact test for categorical data. Tukey's post hoc test was conducted to explore the differences between multiple groups. Pearson correlation was used to assess the correlation between continuous, dichotomous variables, and $\mathrm{HbA} 1 \mathrm{c}$. Categorical variables were converted to dichotomous $(0,1)$ and included in Pearson correlation coefficients.

The association of H.L. and nutritional status assessments with glycemic control as analyzed using multiple linear regressions with a stepwise method. We imputed the variables into the models when $p<0.20$ in the bivariate analysis [15]. In multiple linear regression analyses, the categorical variables with two categories were coded using the dummy coding system, such as sex ( $0=$ male, $1=$ female). For more than two levels, such as treatment modalities, we coded into four categories in the following order; where $0=$ oral antidiabetic therapy (reference category), $1=$ insulin therapy only, $2=$ dual antidiabetic therapy (insulin and oral antidiabetic therapy), and $3=$ diet alone. The categorization is necessary to maintain and include all categories of the variable in the predicting models. A 95\% confidence interval was established. The variance inflation factor (V.I.F.) was 1.07 indicated that the predictors are weakly correlated but not enough to be overly concerned about it. Therefore, multicollinearity is not a problem in the current study.

\section{Results}

\subsection{Recruitment of Respondents}

A total of 665 patients from the database were screened, of which 329 met the study criteria. The main reasons for being excluded from the study included type 1 diabetes, gestational diabetes, hearing or vision problems, renal failure, or having severe illnesses like cancers. We invited all of them, but 329 respondents responded by, of which 310 of them agreed to participate and signed the consent form. The study included a total of 280 respondents who provided $85 \%$ of the response rates (Figure 1).

\subsection{Client History and Health Literacy Levels}

Respondents in this study were in their $50 \mathrm{~s}^{\prime}$ with more than half were females $(55 \%)$, and nearly half $(41.8 \%)$ had low education and diagnosed with diabetes for $1-5$ years $(46.4 \%)$ (Table 1$)$. The mean (SD) HL score was 45.7 (24.6), with nearly $80 \%$ (77.4\%) had either inadequate (55.6\%) or marginal HL $(20.8 \%)$ levels. Only $23.5 \%$ of the respondents had adequate H.L. The average mean (S.D.) H.L. scores for each category were 27.62 (15.92) for inadequate H.L., 60.53 (15.92) for marginal H.L., and 75.89 (9.46) for adequate H.L. Respondents with inadequate H.L. had significantly lower S-TOFHLA scores for numeracy and reading skills. They spent more time taking the test. Inadequate H.L. levels were more common among older and female respondents; housewives, they attained lower than middle 
school, had a shorter diabetes duration, and were mostly on oral agents. Respondents with inadequate H.L. levels were significantly older than those with marginal and adequate H.L. levels $(p<0.05)$.

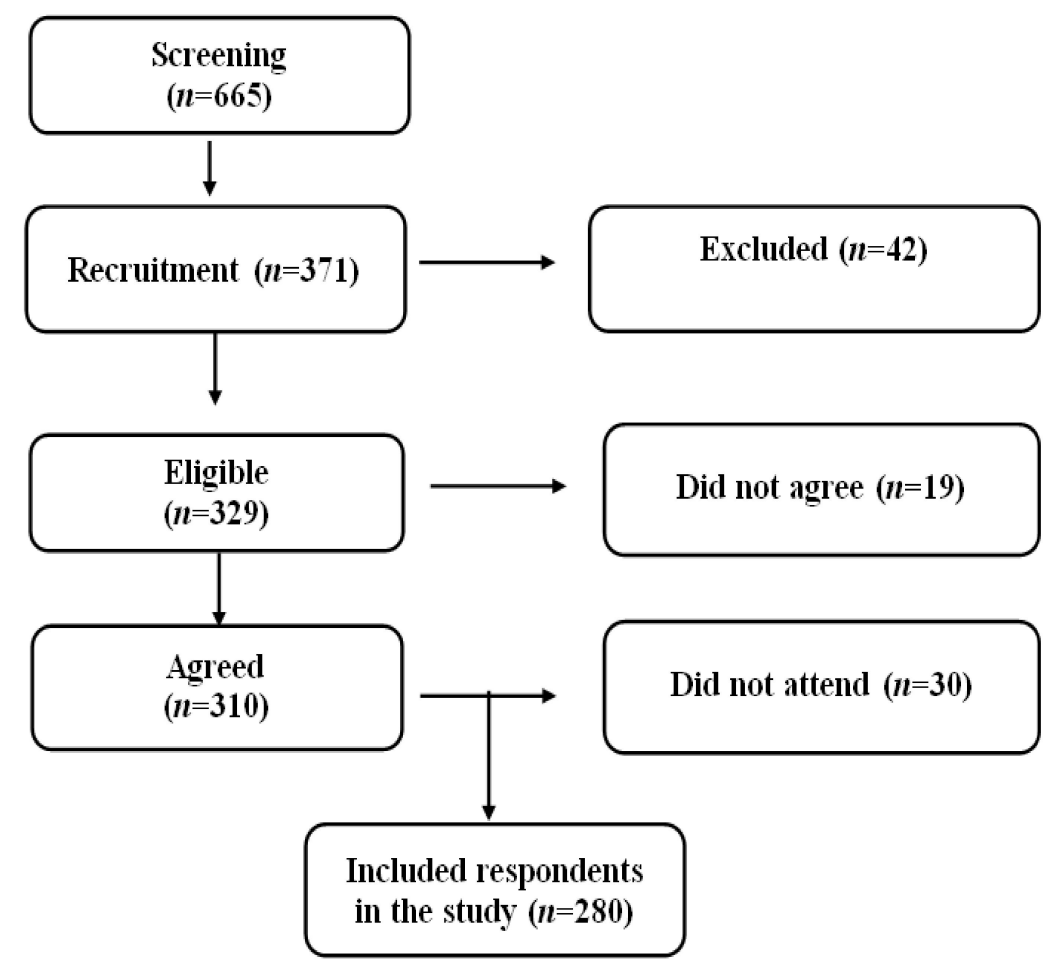

Figure 1. Screening and Recruitment of the Study Respondents.

\subsection{Anthropometry, Biochemical, and Health Literacy Levels}

The average $\mathrm{HbA} 1 \mathrm{c}$ was 10.0 (2.7\%), with $86.8 \%$ had poor glycemic control indicated as $\mathrm{HbA} 1 \mathrm{c}$ of $>7 \%$. Respondents with inadequate HL had a significantly higher HbA1c levels (Mean (SD) $=10.6$ $(2.6 \%))$ than those with marginal and adequate HL $(p<0.001)$. On the other hand, respondents with adequate HL had significantly better total cholesterol levels (mean $(\mathrm{SD})=9.4(2.6 \mathrm{mmol} / \mathrm{L}))$, LDL-cholesterol $($ mean $(\mathrm{SD})=6.4(2.1 \mathrm{mmol} / \mathrm{L}))$, and systolic blood pressure $($ mean $(\mathrm{SD})=135.3(25.8$ $\mathrm{mmHg})$ ) than those respondents who had inadequate and marginal HL. Mean Body Mass Index of respondents was within obesity (mean $\left.(\mathrm{SD})=32.66(15.11) \mathrm{kg} / \mathrm{m}^{2}\right)($ Table 2$)$. 
Table 1. Socio-demographic and medical status of respondents according to the health literacy levels.

\begin{tabular}{|c|c|c|c|c|c|}
\hline \multirow[b]{2}{*}{ Variables } & \multicolumn{3}{|c|}{ Health Literacy Levels } & \multirow[b]{2}{*}{$\begin{array}{c}\text { Total } \\
(n=280) \text { Mean (SD) }\end{array}$} & \multirow[b]{2}{*}{$p$-Value ${ }^{\dagger}$} \\
\hline & $\begin{array}{c}\text { Inadequate } \\
(n=156,56.7 \%) \\
\text { Mean (SD) }\end{array}$ & $\begin{array}{c}\text { Marginal } \\
(n=58 ; 20.7 \%) \\
\text { Mean }(\mathrm{SD})\end{array}$ & $\begin{array}{c}\text { Adequate } \\
(n=66 ; 23.5 \%) \\
\text { Mean (SD) }\end{array}$ & & \\
\hline Age (years) & $50.02(10.54)^{\mathrm{a}}$ & $49.49(7.16)^{a}$ & $46.37(11.34)^{b}$ & $49.65(10.29)$ & 0.05 \\
\hline Monthly income (USD) & $\begin{array}{c}825.16 \\
(1306.69)\end{array}$ & $\begin{array}{c}892.96 \\
(621.12)\end{array}$ & $\begin{array}{c}943.01 \\
(919.07)\end{array}$ & $\begin{array}{c}867.07 \\
(1107.49)\end{array}$ & 0.755 \\
\hline S-TOFHLA numeracy ${ }^{\hat{e}}$ & $8.55(7.04)^{a}$ & $16.29(4.89)^{b}$ & $25.00(6.22)^{c}$ & $14.03(9.37)$ & $<0.001$ \\
\hline S-TOFHLA reading $\hat{\mathrm{g}}$ & $19.31(11.98)^{\mathrm{a}}$ & $44.52(6.10)^{b}$ & $50.80(8.55)^{c}$ & $31.96(17.62)$ & $<0.001$ \\
\hline S-TOFHLA total & $27.62(15.92)^{\mathrm{a}}$ & $60.53(15.92)^{b}$ & $75.89(9.46)^{c}$ & $45.82(24.68)$ & $<0.001$ \\
\hline S-TOFHLA time (min) & $22.50(2.13)^{\mathrm{a}}$ & $20.93(2.67)^{b}$ & $17.38(2.80)^{\mathrm{c}}$ & $20.97(3.19)$ & $<0.001$ \\
\hline Variables & $n(\%)$ & $n(\%)$ & $n(\%)$ & $n(\%)$ & $p$-Value * \\
\hline $\begin{array}{c}\text { Sex } \\
\text { Male } \\
\text { Female }\end{array}$ & $\begin{array}{l}57(36.5) \\
99(63.5)\end{array}$ & $\begin{array}{l}27(46.6) \\
31(53.4)\end{array}$ & $\begin{array}{l}43(65.2) \\
23(34.8)\end{array}$ & $\begin{array}{l}127(45.4) \\
153(54.6)\end{array}$ & $<0.001$ \\
\hline $\begin{array}{c}\text { Marital status } \\
\text { Single } \\
\text { Married } \\
\text { Widowed (widower) }\end{array}$ & $\begin{array}{c}18(11.5) \\
135(86.5) \\
3(1.9)\end{array}$ & $\begin{array}{c}6(10.3) \\
49(84.5) \\
3(5.2)\end{array}$ & $\begin{array}{c}6(9.1) \\
58(87.9) \\
2(3.0)\end{array}$ & $\begin{array}{c}30(10.7) \\
242(86.4) \\
8(2.9)\end{array}$ & $0.757^{\mathrm{F}}$ \\
\hline $\begin{array}{c}\text { Education level } \\
\text { Low } \\
\text { Middle school } \\
\text { High school and above }\end{array}$ & $\begin{array}{l}84(53.8) \\
37(23.7) \\
35(22.4)\end{array}$ & $\begin{array}{l}23(39.7) \\
16(27.6) \\
19(32.8)\end{array}$ & $\begin{array}{l}10(15.2) \\
28(42.4) \\
28(42.4)\end{array}$ & $\begin{array}{l}117(41.8) \\
81(28.9) \\
82(29.3)\end{array}$ & $<0.001$ * \\
\hline $\begin{array}{l}\text { Employment } \\
\text { Employee } \\
\text { Retired } \\
\text { Self-employed } \\
\text { Housewife } \\
\text { Unemployed }\end{array}$ & $\begin{array}{c}30(19.2) \\
17(10.9) \\
22(14.1) \\
82(52.6) \\
5(3.2)\end{array}$ & $\begin{array}{c}23(39.7) \\
2(3.4) \\
4(6.9) \\
25(43.1) \\
4(6.9)\end{array}$ & $\begin{array}{c}34(51.5) \\
6(9.1) \\
11(16.7) \\
11(16.7) \\
4(6.1)\end{array}$ & $\begin{array}{c}87(31.1) \\
25(8.9) \\
37(13.2) \\
118(42.1) \\
13(4.6)\end{array}$ & $<0.001^{\mathrm{F}}$ \\
\hline
\end{tabular}


Table 1. Cont.

\begin{tabular}{|c|c|c|c|c|c|}
\hline \multirow[b]{2}{*}{ Variables } & \multicolumn{3}{|c|}{ Health Literacy Levels } & \multirow[b]{2}{*}{$\begin{array}{c}\text { Total } \\
(n=280) \text { Mean (SD) }\end{array}$} & \multirow[b]{2}{*}{$p$-Value ${ }^{\dagger}$} \\
\hline & $\begin{array}{c}\text { Inadequate } \\
(n=156,56.7 \%) \\
\text { Mean (SD) }\end{array}$ & $\begin{array}{c}\text { Marginal } \\
(n=58 ; 20.7 \%) \\
\text { Mean (SD) }\end{array}$ & $\begin{array}{c}\text { Adequate } \\
(n=66 ; 23.5 \%) \\
\text { Mean (SD) }\end{array}$ & & \\
\hline \multicolumn{6}{|l|}{ Family History of D.M. } \\
\hline Yes & $130(83.3)$ & $43(74.1)$ & $51(77.3)$ & $224(80.0)$ & $0.268 *$ \\
\hline No & $26(16.7)$ & $15(25.9)$ & $15(22.7)$ & $56(20.0)$ & \\
\hline \multicolumn{6}{|l|}{ Years with Diabetes } \\
\hline $1-5$ years & $71(45.5)$ & $24(41.4)$ & $35(53.0)$ & $130(46.4)$ & \multirow{3}{*}{$0.005^{*}$} \\
\hline $6-10$ years & $65(41.7)$ & $17(29.3)$ & $14(21.2)$ & $96(34.3)$ & \\
\hline 11 years and more & $20(12.8)$ & $17(29.3)$ & $17(25.8)$ & $54(19.3)$ & \\
\hline \multicolumn{6}{|l|}{ Treatment Modalities } \\
\hline Oral antidiabetic therapy & $73(46.8)$ & $31(53.4)$ & $19(28.8)$ & $123(43.9)$ & \multirow{4}{*}{$<0.001^{\mathrm{J}}$} \\
\hline Insulin therapy only & $10(6.4)$ & $8(13.8)$ & $19(28.8)$ & $37(13.2)$ & \\
\hline Dual antidiabetic therapy & $68(43.6)$ & $19(32.8)$ & $24(36.4)$ & $111(39.6)$ & \\
\hline Diet alone & $5(3.2)$ & $0(0.0)$ & $4(6.1)$ & $9(3.2)$ & \\
\hline \multicolumn{6}{|l|}{ Co-morbidities } \\
\hline Yes & $103(66.0)$ & $44(75.9)$ & $43(65.2)$ & $190(67.9)$ & \multirow[t]{2}{*}{$0.339 *$} \\
\hline No & $53(34.0)$ & $14(24.1)$ & $23(34.8)$ & $90(32.1)$ & \\
\hline
\end{tabular}

* The Chi-square test or ${ }^{\mathrm{F}}$ Fisher Exact test was used for categorical variables; ${ }^{\hat{e}}$ : scored out of $30 ; \hat{\mathrm{s}}_{\text {: }}$ scored out of 70 ; ${ }^{\dagger}$ one-way analysis of variance (ANOVA), for means of continuous variables; N (\%). Data are presented as number and percentage, S.D. = standard deviation, US\$ = United States Dollar, D.M. = diabetes mellitus. ${ }^{a, b, c}=$ means in a row with different superscript letters are significantly different among groups with post hoc tests. S-TOFHLA = short-form Test of Functional Health Literacy in Adults. The $p$-value is significant at the 0.05 level. 
Table 2. Anthropometrics and biochemical data of respondents according to the health literacy levels.

\begin{tabular}{|c|c|c|c|c|c|}
\hline \multirow[b]{2}{*}{ Characteristics } & \multicolumn{3}{|c|}{ Health Literacy Level } & \multirow[b]{2}{*}{$\begin{array}{c}\text { Total } \\
(n=280,100 \%) \\
\text { Mean (SD) }\end{array}$} & \multirow[b]{2}{*}{$p$-Value } \\
\hline & $\begin{array}{c}\text { Inadequate } \\
(n=156,56.7 \%) \\
\text { Mean (SD) }\end{array}$ & $\begin{array}{c}\text { Marginal } \\
(n=58 ; 20.7 \%) \\
\text { Mean (SD) }\end{array}$ & $\begin{array}{c}\text { Adequate } \\
(n=66 ; 23.5 \%) \\
\text { Mean (SD) }\end{array}$ & & \\
\hline Body Mass Index $\left(\mathrm{kg} / \mathrm{m}^{2}\right)$ & $32.99(13.22)$ & $31.11(13.77)$ & $33.33(19.9)$ & $32.66(15.11)$ & 0.680 \\
\hline $\operatorname{HbA1c}(\%)$ & $10.63(2.61)^{a}$ & $9.02(2.03)^{b}$ & $9.13(2.34)^{b}$ & $9.99(2.66)$ & $<0.001$ \\
\hline FBG (mg/dL) & $269.20(116.14)$ & $246.13(106.64)$ & $235.35(111.33)$ & $256.44(113.68)$ & 0.09 \\
\hline Total Cholesterol (mg/dL) & $196.75(42.24)^{\mathrm{a}}$ & $199.03(54.23)^{\mathrm{a}}$ & $168.34(46.43)^{b}$ & $190.55(42.2)$ & $<0.001$ \\
\hline LDL-C (mg/dL) & $143.72(47.41)^{\mathrm{a}}$ & $139.95(53.01)^{\mathrm{a}}$ & $114.42(37.22)^{b}$ & $136.00(48.00)$ & $<0.001$ \\
\hline HDL-C (mg/dL) & $44.33(20.53)$ & $44.42(9.46)$ & $42.54(12.03)$ & $43.99(16.99)$ & 0.760 \\
\hline Triglyceride (mg/dL) & $214.43(110.27)$ & $215.84(102.52)$ & $190.03(105.33)$ & 208.99 (107.66) & 0.260 \\
\hline Systolic BP (mmHg) & $138.23(20.63)^{a}$ & $138.78(24.78)^{\mathrm{a}}$ & $125.15(33.87)^{b}$ & $135.33(25.77)$ & 0.001 \\
\hline Diastolic BP (mmHg) & $83.24(10.8)$ & $88.06(20.87)$ & $83.8(10.48)$ & $84.333(13.55)$ & 0.060 \\
\hline
\end{tabular}

Note: one-way ANOVA was conducted; $\mathrm{n}(\%)$. Data are presented as number and percentage. $\mathrm{SD}=$ standard deviation; HbA1c $=\mathrm{Glycated}$ hemoglobin; FBG $=$ fasting blood glucose; $\mathrm{mg} / \mathrm{dL}=$ milligram/deciliter; LDL-C $=$ low-density lipoprotein cholesterol; HDL-C $=$ high-density lipoprotein cholesterol; $\mathrm{BP}=$ blood pressure; ${ }^{\mathrm{a}, \mathrm{b}}=\mathrm{means}$ in a row with different superscript letters are significantly different among groups with post hoc test. The $p$-value is significant at the 0.05 level. 


\subsection{Association of Health Literacy and Nutritional Status Assessments with Glycemic Control}

Table 3 shows a total of 20 variables were associated with $\mathrm{HbA1c}$ levels at the bivariate levels. These included age, income, presence with co-morbidities, B.M.I., F.B.G., T.C., diastolic B.P., H.L. score, oral antidiabetic therapy, dual antidiabetic therapy (insulin with oral agents), insulin therapy only, diet alone, low education, middle school, high school, and above, employed, retired, self-employed, 1-5 years present with T2DM, and 6-10 years present with T2DM.

Table 3. Factors associated with glycemic control ( $\mathrm{HbA} 1 \mathrm{c})$ of the respondents.

\begin{tabular}{cccc}
\hline No. & Variables & $r$ & $p$-Value \\
\hline 1 & Age (years) & -0.094 & 0.11 \\
2 & Income (USD) & -0.272 & $<0.001$ \\
3 & Presence of the co-morbidities & 0.118 & 0.05 \\
4 & Body mass index $\left(\mathrm{kg} / \mathrm{m}^{2}\right)$ & -0.118 & 0.05 \\
5 & Fasting blood glucose $(\mathrm{mg} / \mathrm{dL})$ & 0.153 & 0.01 \\
6 & Total cholesterol $(\mathrm{mg} / \mathrm{dL})$ & 0.158 & 0.008 \\
7 & Diastolic blood pressure $(\mathrm{mmHg})$ & -0.107 & 0.07 \\
8 & Health literacy score & -0.301 & $<0.001$ \\
9 & Oral antidiabetic drugs therapy & -0.288 & $<0.001$ \\
10 & Dual antidiabetic therapy & 0.241 & $<0.001$ \\
11 & Insulin therapy only & 0.081 & 0.001 \\
12 & Diet alone & 0.081 & 0.18 \\
13 & Low education & 0.190 & 0.001 \\
14 & Middle school & -0.121 & 0.04 \\
15 & High school \& above & -0.085 & 0.15 \\
16 & Employee & -0.186 & 0.002 \\
17 & Retired & -0.091 & 0.13 \\
18 & Self-employed & 0.242 & 0.001 \\
19 & 1-5 years present with diabetes & -0.158 & 0.008 \\
20 & 6-10 years present with diabetes & 0.110 & 0.06 \\
\hline
\end{tabular}

$\mathrm{r}=$ Pearson correlation coefficients; HbA1c = Glycated hemoglobin. The $p$-value is significant at the 0.05 level.

\subsection{Factors Predicting Glycemic Control (HbA1c)}

Table 4 shows the factors that significantly predicted the HbA1c levels included HL score, self-employment, dual anti-diabetic therapy, insulin alone, and FBG (Adjusted $R^{2}=0.21, F(5,279)=15.698$, $p<0.001$ ). These variables explained $21 \%$ of the variability of $\mathrm{HbA} 1 \mathrm{c}$ in this study. Among other factors in the model, the H.L. score contributed strongly to the HbA1c levels. For each 1-point decreased in the HL score, the HbA1c value increased by $0.32(p<0.001)$.

Table 4. Predictive factors for $\mathrm{HbA1c}$ levels.

\begin{tabular}{lcccccc}
\hline \multicolumn{1}{c}{ Variables } & $\mathbf{B}(\mathbf{9 5} \% \mathbf{C I})$ & $\boldsymbol{\beta}$ & $\mathbf{R}^{\mathbf{2}}$ & ${\text { Adjusted } \mathbf{R}^{\mathbf{2}}}$ & $\mathbf{t}$ & $\boldsymbol{p}$-Value \\
\hline HL score using S-TOFHLA & -0.02 & -0.32 & 0.09 & 0.09 & -5.90 & $<0.001$ \\
\hline Employment vs. employees & & & & & & \\
\hline Self-employed & 0.87 & 0.19 & 0.14 & 0.14 & 3.44 & 0.001 \\
\hline $\begin{array}{l}\text { Treatment modalities vs. oral } \\
\text { antidiabetic therapy }\end{array}$ & & & & & & \\
\hline Dual anti-diabetic therapy & 0.82 & 0.25 & 0.18 & 0.17 & 4.52 & $<0.001$ \\
\hline Insulin therapy only & 0.89 & 0.19 & 0.21 & 0.20 & 3.20 & 0.001 \\
\hline Fasting blood glucose & 0.001 & 0.11 & 0.22 & 0.21 & 1.97 & 0.05 \\
\hline
\end{tabular}

S-TOFHLA = A short-form Test of Functional Health Literacy in Adults. B = unstandardized Coefficients, $\mathrm{CI}=$ confidence interval, $\beta=$ standardized Coefficients, $\mathrm{R}^{2}=$ the proportion of variance in the criterion, $\mathrm{t}=\mathrm{t}$-statistic, $\mathrm{HL}=$ health literacy. The $p$-value is significant at the 0.05 level. 


\section{Discussion}

This study shows that the majority of adults with T2DM had inadequate H.L. levels (56\%). This study confirmed that inadequate H.L. contributed to poor glycemic control, together with nutritional status assessments, including self-employment, dual antidiabetic therapy, insulin alone, and F.B.G. These factors explained $21 \%$ of the variability in $\mathrm{HbA} 1 \mathrm{c}$ level. H.L. is an essential factor that predicted poor $\mathrm{HbA} 1 \mathrm{c}$. In diabetes, patients are required to understand the printed information, oral communication, and numeracy to practice self-diabetes care. All of these skills required adequate H.L. to ensure they can quickly navigate the healthcare system that facilitates to achieve optimal glycemic control [28,29].

The current result was similar to other studies conducted among respondents with T2DM in Brazil [30], Pakistan [31], and Iran [32]. All of these studies used S-TOFHLA to assess H.L. S-TOFHLA was the most commonly used and considered a suitable tool to evaluate H.L. among adults with T2DM [16]. S-TOFHLA can be self-administered to assess reading comprehension by determining a patient's ability to read phrases and passages containing numbers using real objects in health care settings [17]. However, the finding was inconsistent with a study conducted in Saudi Arabia among respondents with T2DM. The study used S-TOFHLA, the same tool as in the current study to assess H.L. and found that H.L. was not associated with poor glycemic control but increased B.M.I. [22]. The discrepancy could be due to the difference in the health system in Saudi Arabia compared to Iraq, which explains more patients who had adequate H.L. and glycemic control [22] than the current study.

Self-employed respondents had a higher $\mathrm{HbA1c}$ than those in the employee category. The results were not consistent with previous studies [18,33]. The employment status did not predict glycemic control among Moroccans patients with T2DM [4]. Nevertheless, a study conducted among 325 adults with T2DM attending in Jimma University Teaching Hospital in Ethiopia showed that farmers with diabetes have inadequate glycemic control compared with unemployed patients. Self-employment was associated with more extensive social networks but had more stresses [34].

Besides, dual antidiabetic therapy and insulin therapy alone were significantly associated with poor glycemic control in the current study compared to those on the oral antidiabetic drug category. This finding is in line with other studies conducted among respondents with T2DM in Malaysia [35,36], Singapore [37], and Jordan [38]. A study conducted in Basrah city, Iraq, reported that insulin treatment was a significant factor of an increased risk of poor glycemic control among respondents with T2DM [3]. Lifestyle modification is the first-line therapy in diabetes management. If the optimal glycemic control is unable to achieve, single or dual oral antidiabetic therapy can be given. As diabetes progresses and the target glycemic control is even challenging to achieve, insulin injection would be administered [26]. Thus, that is consistent with our results to show that those with more complex diabetes treatments are the one who had poor glycemic control.

A higher F.B.G. was associated with poor glycemic control. The finding coincides with other studies conducted in Iran among 604 patients with T2DM. They found a strong association between HbA1c and F.B.G. [39]. The similarity in findings could be explained by the lack of control of F.B.G. in daily life lead to poor glycemic control among patients with T2DM.

Respondents with inadequate H.L. were housewives, attained lower education levels, shorter diabetes duration, and received oral antidiabetic therapy alone. The scenario has been commonly observed in previous studies conducted among respondents with T2DM as most of the housewives have no or less education, which difficult for them to be employed [31]. Low education is related to inadequate H.L. among individuals with T2DM because the specific skills are required to understand the printed information, oral communication, and numeracy to practice self-diabetes care. The ability to properly self-manage diabetes would facilitate optimal glycemic control [28,29]. 
This study observed that respondents with adequate H.L. achieved optimal glycemic control and cardiovascular risk controls because they can understand necessary health information to make informed health decisions [40]. This finding shares several similarities with previous results in Spain [41], the United States [15], Brazil [42], and Saudi Arabia [22]. The studies mentioned above found a significant association between adequate H.L. and good HbA1c or diabetes-related outcomes. Respondents with an adequate H.L. usually participate in continuous self-care activities, contributing to consistencies in lifestyle and treatment outcomes, as evidenced by several studies $[15,20,22]$. Therefore, adequate H.L. makes it easy to transfer important health information to diabetes respondents to achieve better glycemic control and avoid diabetes complications [43]. Other nutritional status parameters, including dietary intake and physical activity level, may enhance the prediction to HbA1c. Still, these factors did not include in this current study, which warrants future investigation on this aspect.

\section{Strength and Limitations}

This study used simple random sampling to avoid selection bias. Besides, this study was the first study conducted in Iraq to assess the association of H.L. with glycemic control among respondents with T2DM, using the S-TOFHLA questionnaire. However, little experience with the S-TOFHLA scale among respondents with T2DM poses an obstacle to the authors. Then, illiterate respondents cannot participate in this study. Lastly, the study was conducted at a single hospital where all respondents were living in one city.

\section{Conclusions}

The majority of respondents with T2DM in Basrah, Iraq, had poor glycemic control and inadequate H.L. Respondents with inadequate H.L. levels were significantly older and had a higher $\mathrm{HbA1c}$ than those with marginal and adequate H.L. levels. Meanwhile, respondents with inadequate and marginal H.L. levels had significantly higher total cholesterol, LDL-cholesterol, and systolic blood pressure than the respondents with adequate H.L. levels. Low H.L. scores and nutritional status assessments, including self-employment, dual antidiabetic therapy, insulin alone, and elevated F.B.G. were predictors of poor glycemic control among Iraqi respondents with T2DM. Educational interventions are required to improve H.L. that translates into better glycemic control among diabetes.

Author Contributions: Data cleaning and analysis: S.A.H. \& M.Y.B.-N. Figure drawing and table design: S.A.H. \& M.Y.B.-N. Writing—review \& editing: S.A.H.; M.Y.B.-N.; H.A.S.; S.I.; O.H. \& A.A.M. The authors mentioned in this study have done, read, and approved the final manuscript. The original draft was written by S.A.H., reviewed and edited by all authors, including S.A.H.; M.Y.B.-N.; H.A.S.; S.I.; O.H. \& A.A.M. All authors mentioned have contributed to manuscript editing. S.A.H. \& M.Y.B.-N. completed face and content validation of the questionnaire. Data entry, management, analysis, and interpretation were managed and accomplished by S.A.H. \& M.Y.B.-N. All authors have read and agreed to the published version of the manuscript.

Funding: This study has not received a specific grant from any funding organization in the community or commercial sectors or non-profit.

Acknowledgments: We gratefully acknowledge the valuable collaboration provided by the Chair Diabetes, Endocrine and Metabolism Division, and staff of Faiha Specialized Diabetes, Endocrine and Metabolism Center in Basrah, Iraq. Besides, the respondents willing to participate in this study. We also thank Hayati Abdul Kader for her ongoing statistical consultations in all our statistical analyses.

Conflicts of Interest: We have no conflict of interest to disclose in this study.

\section{References}

1. International Diabetes Federation. Diabetes Atlas; International Diabetes Federation: Brussels, Belgium, 2019, 9th ed. p. 167. Available online: https://www.diabetesatlas.org/en/resources (accessed on 27 July 2020).

2. Mansour, A.A.; Al-Maliky, A.A.; Kasem, B.; Jabar, A.; Mosbeh, K.A. Prevalence of diagnosed and undiagnosed diabetes mellitus in adults aged 19 years and older in Basrah, Iraq. Diabetes Metab. Syndr. Obes. Targets Ther. 2014, 7, 139-144. [CrossRef] [PubMed] 
3. Mansour, A.A.; Alibrahim, N.T.; Alidrisi, H.A.; Alhamza, A.H.; Almomin, A.M.; Zaboon, I.A.; Kadhim, M.B.; Hussein, R.N.; Nwayyir, H.A.; Mohammed, A.G.; et al. Prevalence and correlation of glycemic control achievement in patients with type 2 diabetes in Iraq: A retrospective analysis of a tertiary care database over a 9-year period. Diabetes Metab. Syndr. Clin. Res. Rev. 2020, 14, 265-272. [CrossRef] [PubMed]

4. Chetoui, A.; Kaoutar, K.; Elmoussaoui, S.; Boutahar, K.; El-Kardoudi, A.; Chigr, F.; Najimi, M. Prevalence and determinants of poor glycaemic control: A cross-sectional study among Moroccan type 2 diabetes patients. Int. Health 2020, 1-8. [CrossRef] [PubMed]

5. Abdullah, N.A.; Ismail, S.; Ghazali, S.S.; Juni, M.H.; Kadir, H.; Aziz, N.R. Predictors of Good Glycemic Controls Among Type 2 Diabetes Mellitus Patients in Two Primary Health Clinics, Kuala Selangor. Malays. J. Med. Health Sci. 2019, 15, 58-64. Available online: https://medic.upm.edu.my/upload/dokumen/2019110412111609_ MJMHS_0121 (accessed on 20 July 2020).

6. Alramadan, M.J.; Magliano, D.J.; Almigbal, T.H.; Batais, M.A.; Afroz, A.; Alramadhan, H.J.; Mahfoud, W.F.; Alragas, A.M.; Billah, B. Glycaemic control for people with type 2 diabetes in Saudi Arabia-An urgent need for a review of management plan. B.M.C. Endocr. Disord. 2018, 18, 62. [CrossRef]

7. Gebreyohannes, E.A.; Netere, A.K.; Belachew, S.A. Glycemic control among diabetic patients in Ethiopia: A systematic review and meta-analysis. PLOS ONE 2019, 14, e0221790. [CrossRef]

8. Ali, N.S.; Allela, O.Q.; Salih, H.M.; Ahmed, I.H. Prevalence of Type 2 Diabetes Associated Complications in Kurdistan Region Iraq. J. Basic Clin. Pharm. 2019, 10, 1-6. Available online: https://www.jbclinpharm.org/ abstract/prevalence-of-type-2-diabetes-associatedcomplications-in-kurdistanrnregion-iraq-4984 (accessed on 22 July 2020).

9. Dauod, A. Glycemic control among type 2 diabetic patients attending the Family Medicine Health Center and the Diabetic Health Center in Erbil, Iraq: A comparative study. Zanco J. Med. Sci. 2018, 22, 332-341. [CrossRef]

10. Al-Rasheedi, A.A. Glycemic Control among Patients with Type 2 Diabetes Mellitus in Countries of Arabic Gulf. Int. J. Health Sci. 2015, 9, 345-350. [CrossRef]

11. N'Goran, A.A.; Pasquier, J.; Deruaz-Luyet, A.; Burnand, B.; Haller, D.M.; Neuner-Jehle, S.; Zeller, A.; Streit, S.; Herzig, L.; Bodenmann, P. Factors associated with health literacy in multimorbid patients in primary care: A cross-sectional study in Switzerland. BMJ Open 2018, 8, e018281. [CrossRef] [PubMed]

12. Nutbeam, D. The evolving concept of health literacy. Soc. Sci. Med. 2008, 67, 2072-2078. [CrossRef] [PubMed]

13. Davis, T.C.; Long, S.W.; Jackson, R.H.; Mayeaux, E.J.; George, R.B.; Murphy, P.W.; Crouch, M.A. Rapid estimate of adult literacy in medicine: A shortened screening instrument. Fam. Med. 1993, 25, 391-395. [PubMed]

14. White, R.O.; Osborn, C.Y.; Gebretsadik, T.; Kripalani, S.; Rothman, R.L. Development and validation of a Spanish diabetes-specific numeracy measure: DNT-15 Latino. Diabetes Technol. Ther. 2011, 13, 893-898. [CrossRef] [PubMed]

15. Schillinger, D.; Grumbach, K.; Piette, J.; Wang, F.; Osmond, D.; Daher, C.; Palacios, J.; Sullivan, G.D.; Bindman, A.B. Association of health literacy with diabetes outcomes. JAMA 2002, 288, 475-482. [CrossRef]

16. Al Sayah, F.; Williams, B.; Johnson, J.A. Measuring health literacy in individuals with diabetes: A systematic review and evaluation of available measures. Health Educ. Behav. 2013, 40, 42-55. [CrossRef]

17. Parker, M.; Baker, D.; Williams, M.; Nurss, J. The Test of functional Health Literacy in Adults: A new instrument for measuring patient's literacy skills. J. Gen. Intern. Med. 1995, 10, 537-541. [CrossRef]

18. Abdullah, A.; Liew, S.M.; Salim, H.; Ng, C.J.; Chinna, K. Prevalence of limited health literacy among patients with type 2 diabetes mellitus: A systematic review. PLoS ONE 2019, 14, e0216402. [CrossRef]

19. Abdul-Hasan, A.; Yassin, B. Health Literacy of Diabetic Patients and its Impact on Disease Outcome. J. Fac. Med. 2018, 60, 65-68. [CrossRef]

20. Kim, S.; Love, F.; Quistberg, D.A.; Shea, J.A. Association of health literacy with self-management behavior in patients with diabetes. Diabetes Care 2004, 27, 2980-2982. [CrossRef]

21. Al-Jumaili, A.A.; Al-Rekabi, M.D.; Sorofman, B. Evaluation of instruments to assess health literacy in Arabic language among Iraqis. Res. Soc. Adm. Pharm. 2015, 11, 803-813. [CrossRef] 
22. Mashi, A.H.; Aleid, D.; Almutairi, S.; Khattab, F.; AlMuqawed, A.N.; Khan, S.; AlBanyan, N.; Brema, I.; AlJohani, N.J. The association of health literacy with glycemic control in Saudi patients with type 2 diabetes. Saudi Med. J. 2019, 40, 675-680. [CrossRef]

23. Daniel, W.W. Biostatistic a Foundation for Analysis in the Health Sciences, 9th ed.; Wiley, John Wiley \& Sons, Inc.: Hoboken, NJ, USA, 2009. [CrossRef]

24. Baker, D.W.; Williams, M.V.; Parker, R.M.; Gazmararian, J.A.; Nurss, J. Development of a brief test to measure functional health literacy. Patient Educ. Couns. 1999, 38, 33-42. [CrossRef]

25. Wold Health Organization. WHO expert consultation, Appropriate body-mass index for Asian populations and its implications for policy and intervention strategies. Lancet 2004, 363, 157-163. [CrossRef]

26. Amercan Diabetes Association. Standards of Medical Care in Diabetes. Diabetes Care 2020, 43, S1-S2. [CrossRef]

27. Templeton, F. A Two-Step Approach for Transforming Continuous Variables to Normal: Implications and Recommendations for I.S. Research. Commun. Assoc. Inf. Syst. 2011, 28, 41-58. [CrossRef]

28. Ishikawa, H.; Takeuchi, T.; Yano, E. Measuring functional, communicative, and critical health literacy among diabetic patients. Diabetes Care 2008, 31, 874-879. [CrossRef]

29. Jansen, T.; Rademakers, J.; Waverijn, G.; Verheij, R.; Osborne, R.; Heijmans, M. The role of health literacy in explaining the association between educational attainment and the use of out-of-hours primary care services in chronically ill people: A survey study. B.M.C. Health Serv. Res. 2018, 18, 394. [CrossRef]

30. Gomes, M.B.; Muniz, L.H.; Melo, L.G.; Pizarro, M.H.; Barros, B.S.; Santos, D.C.; Negrato, C.A. Health literacy and glycemic control in patients with diabetes: A tertiary care center study in Brazil. Diabetol. Metab. Syndr. 2020, 12, 11. [CrossRef] [PubMed]

31. Saeed, H.; Saleem, Z.; Naeem, R.; Shahzadi, I.; Islam, M. Impact of health literacy on diabetes outcomes: A cross-sectional study from Lahore, Pakistan. Public Health 2018, 156, 8-14. [CrossRef]

32. Salimi, M.; Sarchahi, S.; Zolfaghari, P.; Daghyanous, B.; Mozaffari, H.; Montazeri, M.; Sohrabi, M.B. Health Literacy among Patients with Diabetes Mellitus Type 2 in Northeast Area of Iran. Int. J. Health Stud. 2017, 3, 14-18. [CrossRef]

33. Wan, W.; Juni, M.; Ariffin, A.; Rahman, Z. Factors Associated with Glycaemic Control among Type 2 Diabetes Mellitus Patients. Int. J. Public Health Clin. Sci. 2016, 3, 89-102. [CrossRef]

34. Belkic, K.L.; Landsbergis, P.A.; Schnall, P.L.; Baker, D. Is job strain a major source of cardiovascular disease risk? Scand. J. Work. Environ. Health 2004, 30, 85-128. [CrossRef] [PubMed]

35. Ahmad, N.S.; Ramli, A.; Islahudin, F.; Paraidathathu, T. Medication adherence in patients with type 2 diabetes mellitus treated at primary health clinics in Malaysia. Patient Prefer. Adherence 2013, 7, 525-530. [CrossRef] [PubMed]

36. Ahmad, N.S.; Islahudin, F.; Paraidathathu, T. Factors associated with good glycemic control among patients with type 2 diabetes mellitus. J. Diabetes Investig. 2014, 5, 563-569. [CrossRef]

37. Quah, J.H.; Liu, Y.P.; Luo, N.; How, C.H.; Tay, E.G. Younger adult type 2 diabetic patients have poorer glycaemic control: A cross-sectional study in a primary care setting in Singapore. B.M.C. Endocr. Disord. 2013, 13, 18. [CrossRef]

38. Khattab, M.; Khader, Y.S.; Al-Khawaldeh, A.; Ajlouni, K. Factors associated with poor glycemic control among patients with type 2 diabetes. J. Diabetes Its Complicat. 2010, 24, 84-89. [CrossRef]

39. Ghazanfari, Z.; Haghdoost, A.A.; Alizadeh, S.M.; Atapour, J.; Zolala, F. A Comparison of HbA1c and Fasting Blood Sugar Tests in General Population. Int. J. Prev. Med. 2010, 1, 187-194. [CrossRef]

40. Magnani, J.W.; Mujahid, M.S.; Aronow, H.D.; Cené, C.W.; Dickson, V.V.; Havranek, E.; Morgenstern, L.B.; Paasche-Orlow, M.K.; Pollak, A.; Willey, J.Z.; et al. Health Literacy and Cardiovascular Disease: Fundamental Relevance to Primary and Secondary Prevention: A Scientific Statement From the American Heart Association. Circulation 2018, 138, 48-74. [CrossRef]

41. Fernandez-Silva, M.J.; Alonso-Gonzalez, A.; Gonzalez-Perez, E.; Gestal-Otero, J.J.; Diaz-Gravalos, G.J. Health literacy in patients with type 2 diabetes: A cross-sectional study using the HLS-EU-Q47 questionnaire. Semergen 2019, 45, 30-36. [CrossRef] 
42. Souza, J.G.; Apolinario, D.; Magaldi, R.M.; Busse, A.L.; Campora, F.; Jacob-Filho, W. Functional health literacy and glycaemic control in older adults with type 2 diabetes: A cross-sectional study. BMJ Open 2014, 4, 4180. [CrossRef]

43. Zarcadoolas, C.; Pleasant, A.; Greer, D.S. Understanding health literacy: An expanded model. Health Promot. Int. 2005, 20, 195-203. [CrossRef] [PubMed]

Publisher's Note: MDPI stays neutral with regard to jurisdictional claims in published maps and institutional affiliations.

(C) 2020 by the authors. Licensee MDPI, Basel, Switzerland. This article is an open access article distributed under the terms and conditions of the Creative Commons Attribution (CC BY) license (http://creativecommons.org/licenses/by/4.0/). 